\title{
A IMPORTÂNCIA DO PROCESSO ADMINISTRATIVO FISCAL
}

\author{
SERGIO ANDRÉ R. G. DA SILVA*
}

1. Introdução. 2. O papel dos tributos em um Estado Social. 3. A inclinação dos contribuintes ao inadimplemento dos deveres fiscais. 4. Delegação das atividades de arrecadação tributária aos contribuintes. 5. A relevância assumida pelas atividades de fiscalização. 6. Análise das premissas firmadas. 7. A importância do processo administrativo fiscal.

\section{Introdução}

No ano de 1987, veio a lume o artigo do Professor Carlos Ari Sundfeld intitulado "A Importância do Procedimento Administrativo", cuja premissa era a de que o processo administrativo é instrumento essencial para o controle da atividade de conversão dos fins previstos no ordenamento jurídico em atos administrativos. ${ }^{1}$

Desde a publicação do citado trabalho, houve um perceptível crescimento da produção teórica sobre o processo administrativo, inclusive sobre o processo administrativo fiscal, sem, contudo, que se lograsse o reconhecimento de que este é de vital importância para o funcionamento do Sistema Tributário como um todo, podendo-se afirmar, com Antonio Berliri, que os problemas relativos ao controle da legalidade dos atos administrativos fiscais são alguns dos problemas centrais do Direito Tributário, "na medida que de sua solução depende o correto funcionamento do sistema tributário".2

1 SUNDFELD, Carlos Ari. A Importância do Procedimento Administrativo. Revista de Direito Público, São Paulo, n. 84, out.-dez. 1987, p. 64-74.

* Professor do Curso de Especialização em Direito Tributário da Universidade Federal Fluminense. Mestre em Direito pela Universidade Gama Filho.

2 BERLIRI, Antonio. Per un Miglior Funzionamento della Giustizia Tributaria. In: Scritti Scelti di Diritto Tributario. Milano: Giuffrè, 1990. p. 899. 
A notável importância do processo administrativo no Brasil é consequiência do estado da arte do Sistema Tributário pátrio, onde:

(a) os tributos aparecem como forma principal de custeio das atividades estatais;

(b) os contribuintes muitas vezes não se sentem inclinados a efetuar o pagamento dos tributos devidos;

(c) as atividades de liquidação e arrecadação tributárias foram delegadas aos sujeitos passivos; e

(d) para controle dos pagamentos devidos pelos contribuintes, grandes poderes foram atribuídos à Administração Fazendária.

Os fatores acima apontados, que serão objeto de exame adiante, acarretam a necessidade não só do estudo do processo administrativo, seus fundamentos e regime jurídico, mas também a premência de sua valorização por parte dos contribuintes, a qual depende do reconhecimento de sua importância por parte do Poder Público. Infelizmente, o cenário atual está bastante divorciado do ideal.

Com efeito, o que se tem verificado, tomando, por exemplo, as manifestações da Fazenda Nacional, é uma depreciação e um desprestígio do processo administrativo, que tem culminado na tentativa de adoção de medidas que tendem a acarretar a sua mais completa inocuidade, como a defesa do recurso hierárquico ao Ministro da Fazenda contra decisão proferida pelos Conselhos de Contribuintes ou pela Câmara Superior de Recursos Fiscais e da possibilidade de ajuizamento, pela Procuradoria Geral da Fazenda Nacional, de ação judicial questionando essas mesmas decisões. ${ }^{3}$

Diante do exposto, o propósito desse estudo consiste na análise do cenário atual da tributação no Brasil, examinando-se o papel do processo administrativo como instrumento essencial de manutenção da integridade do Sistema Tributário, visando demonstrar que, embora tenhamos dado alguns passos, especialmente em sede doutrinária, em direção à valorização do processo administrativo fiscal, há um longo caminho ainda a ser percorrido.

\section{O papel dos tributos em um Estado Social}

Já tive a oportunidade de analisar, em outra sede, à qual remetemos o leitor, as linhas gerais da evolução histórica do Estado Liberal até o advento do Estado Social. ${ }^{4}$

Para os propósitos do presente estudo é importante apenas ressaltar que o chamado Estado Social caracteriza-se pela intervenção estatal nas relações privadas

3 Cf. SILVA, Sergio André R. G. da Silva. Questionamento Judicial, pela Fazenda Nacional, de Decisão Administrativa Final - Análise do Parecer PGFN/CRJ n 1.087/2004. Revista Dialética de Direito Tributário, São Paulo, n. 109, out. 2004, p. 90-99.

4 SILVA, Sergio André R. G. da Silva. Controle Administrativo do Lançamento Tributário: O Processo Administrativo Fiscal. Rio de Janeiro: Lumen Juris, 2004. p. 1-13. 
e no exercício de direitos individuais, assim como pelo desenvolvimento das prestações de previdência e seguridade sociais, como é possível inferir da seguinte passagem de Paulo Bonavides:

Quando o Estado, coagido pela pressão das massas, pelas reivindicações que a impaciência do quarto estado faz ao poder político, confere, no Estado constitucional ou fora deste, os direitos do trabalho, da previdência, da educação, intervém na economia como distribuidor, dita o salário, manipula a moeda, regula os preços, combate o desemprego, protege os enfermos, dá ao trabalhador e ao burocrata a casa própria, controla as profissões, compra a produção, financia as exportações, concede crédito, institui comissōes de abastecimento, provê necessidades individuais, enfrenta crises econômicas, coloca na sociedade toas as classes na mais estreita dependência de seu poderio econômico, político e social, em suma, estende sua influência a quase todos os domínios que dantes pertenciam, em grande parte, à área de iniciativa individual, nesse instante o Estado pode, com justiça, receber a denominação de Estado Social. ${ }^{5}$

Ao se proceder à análise das disposições contidas na Constituição Federal de 1988 percebe-se que a mesma é a Constituição de um Estado Social, como reconhece o próprio Professor Paulo Bonavides em outra obra. ${ }^{6}$ Dessa forma, o Estado brasileiro pode ser examinado como um Estado que assumiu a realização de diversas atividades que antes se encontravam na esfera de atribuições das pessoas de Direito Privado, acumulando funções de prestação de serviços, regulação e fomento das atividades particulares.

É importante observar, então, que o crescimento das atividades estatais trouxe consigo a necessidade de recursos para o seu custeio e assim a transformação dos

5 Do Estado Liberal ao Estado Social. 7. ed. São Paulo: Malheiros, 2001 p. 186. Sobre a transição do Estado Liberal para o Estado Social são pertinentes as palavras de Maria Teresa de Melo Ribeiro: "A alteração das relaçōes entre o Estado e a sociedade, e a conseqüente transformação da Administração Pública de autoritária e agressiva em participada e prestadora de serviços, fruto da evolução do Estado Liberal para o Estado Social de Direito, pode ser aprofundada, sem dúvida, como uma das circunstâncias mais marcantes em direção à afirmação e defesa da imparcialidade administrativa. A uma relação de quase inimizade entre o Estado e o cidadão substitui-se uma relação de intimidade que, apesar da sua natureza, ou talvez mesmo por causa dela, gerará novas tensões: 'da defesa da não intervenção do Estado na sociedade, como forma de proteção do cidadão, passa-se a reclamar a intervenção do Estado na vida econômica e social como instrumento de realização individual'. Ao chamar a si a satisfação regular e contínua da maior parte das necessidades coletivas de segurança, cultura e bem-estar, o Estado lança a sua proteção a todas as esferas da vivência individual e transforma-se numa agência de repartição e distribuição de riqueza. 'Por isso alguns falam no Estado-Providência, um Estado que se sente na obrigação de derramar sobre os seus membros todos os benefícios do progresso. colocando-se ao serviço de uma sociedade mais justa, especialmente para os mais desfavorecidos" (RIBEIRO, Maria Teresa de Melo. Principio da Imparcialidade da Administraçāo Pública. Coimbra: Almedina, 1996. p. 58).

6 Curso de Direito Constitucional. 11. ed. São Paulo: Malheiros, 2001. p. 371. 
Estados ocidentais em Estados Fiscais, os quais dependem da arrecadação tributária para a consecução de seus fins.

Há, assim, importante relação entre o desenvolvimento da participação estatal na vida das pessoas de Direito Privado e a ampliação das carências arrecadatórias do Poder Público, que passa a ter na arrecadação tributária fonte de recursos indispensáveis para o custeio de suas atividades. Como destaca Juan Manuel Barquero Estevan:

Faz já alguns anos, em um trabalho que pode ser tido já por um clássico na literatura sobre o Estado social, Ernst Forstoff afirmava que o Estado fiscal ou impositivo constitui o vínculo indispensável de união entre os princípios do Estado de Direito e Estado social, porque somente através das possibilidades de ingerência do Estado impositivo pode-se garantir o desenvolvimento do Estado social, sob uma estrita observância, ao próprio tempo, das formas do Estado de Direito e, concretamente, do respeito do Direito de propriedade. Apontava, assim, a tese de que a configuração do Estado como "impositivo" constitui um pressuposto funcional do Estado social, pois este só pode alcançar seus objetivos recorrendo ao imposto como instrumento financeiro. ${ }^{7}$

Em linha com o que restou asseverado acima está o entendimento do Professor da Universidade de Nova Iorque Stephen Holmes e do Professor da Universidade de Chicago Cass R. Sunstein, abaixo transcrito:

A Declaração de Independência estabelece que "para assegurar esses direitos, Governos são estabelecidos entre os homens". À óbvia verdade de que direitos dependem de governos deve ser acrescido um corolário lógico, rico em implicą̧ões: direitos custam dinheiro. Direitos não podem ser protegidos ou efetivados sem financiamento e apoio públicos. Isso é verdade tanto para os direitos primitivos como para os direitos modernos, para os direitos dos Americanos antes e depois do New Deal de Frankiln Delano Roosevelt. Tanto o direito ao bem-estar quanto o direito à propriedade privada têm custos públicos. $\mathrm{O}$ direito à liberdade contratual não custa menos que o direito à saúde, o direito à liberdade de expressão não custa menos que o direito a uma habitação decente. Todos os direitos dependem do tesouro público. $^{8}$

No contexto de um Estado Social, portanto, a tributação passa a ser a fonte de custeio de todos os deveres estatais, muitos deles elevados a direitos fundamentais pela Constituição, como aqueles relativos, por exemplo, à saúde e à educação.

7 ESTEVAN, Juan Manuel Barquero. La Función del Tributo en el Estado Democrático de Derecho. Madrid: Centro de Estudios Constitucionales, 2002. p. 33.

8 HOLMES. Stephen; SUNSTEIN, Cass R. The Cost of Rights: Why Liberty Depends on Taxes. New York: W. W. Norton \& Company, 1999. p. 15. 
É nesse cenário que deve ser examinada a natureza do dever daqueles que ostentam capacidade contributiva de contribuírem com o erário público, dever este que, como pretendido pelo Professor Casalta Nabais, pode sim ser compreendido como um dever fundamental, na medida em que de seu adimplemento depende 0 custeio, pelo Estado, de todos os direitos fundamentais previstos na Constituição Federal. ${ }^{9}$

Fixa-se, assim, a primeira premissa deste estudo: em um Estado onde o Poder Público assumiu diversas atribuições referentes à garantia da saúde, da educação, da moradia, à previdência e seguridade sociais, ao fomento das atividades particulares, entre outras, os tributos passam a ter um papel fundamental, dependendo o Estado dos mesmos para financiar todas as atividades que lhe foram atribuidas pela Constituição Federal.

\section{A inclinação dos contribuintes ao inadimplemento dos deveres fiscais}

No item anterior fez-se apologia à relevância dos tributos em um Estado Social. Contraditoriamente, deve-se analisar no presente item a inclinação dos contribuintes ao inadimplemento dos deveres fiscais.

É corrente o reconhecimento de que, no mais das vezes, os contribuintes não se sentem "psicologicamente motivados" ao comprimento de suas obrigações tributárias, de modo que é possível defender, como salienta Heleno Tôrres, que, em termos sociológicos "a primeira e mais instintiva reação do contribuinte perante exigências tributárias é teoreticamente aquela de abster-se ao seu cumprimento". ${ }^{10}$

Em nosso país, tal desânimo dos contribuintes em contribuir para os cofres públicos é normalmente justificado alegando-se que o pagamento dos tributos não traz qualquer espécie de retorno ou retribuição, de forma que, independentemente dos pagamentos feitos os serviços públicos continuam tendo uma péssima qualidade. Em suma, o contribuinte não se sente "psicologicamente motivado" ao recolhimento pois não percebe qualquer contrapartida estatal que justifique sua privação de recursos em benefício do Estado.

Sobre esse ponto de vista é possível apresentar duas ponderações.

Em primeiro lugar, é possível asseverar que diante do fenômeno da concentração de renda que atinge diversas nações, do qual o Brasil é triste exemplo, vive-se hoje um período em que se buscam novos fundamentos para a tributação. $O$ dilema é o seguinte:

Como visto, o Estado-Administração necessita cada vez mais de recursos para fazer face às despesas com saúde, previdência, segurança, educação, fomento, pesquisa, etc. Para tanto, são necessárias a instituição e coleta de tributos.

9 NABAIS, José Casalta. O Dever Fundamental de Pagar Impostos. Coimbra: Almedina, 1998.

10 TÔRRES, Heleno. Direito Tributário e Direito Privado. São Paulo: Revista dos Tribunais, 2003. p. 173. 
Todavia, tomando ainda o exemplo do Brasil, verifica-se que grande parte da população não detém condições econômicas sequer para o custeio de suas necessidades mais fundamentais, quanto mais para contribuir para o erário público (embora o faça, mesmo sem saber, devido à sistemática de tributação indireta aqui adotada). Nesse contexto, o encargo do custeio da tributação direta recai sobre as classes mais abastadas. principalmente a classe média.

Ocorre que a necessidade dos serviços públicos é inversamente proporcional à condição econômica do sujeito, de forma que aqueles mais ricos, que em princípio teriam melhores condições de contribuir para o financiamento das atividades estatais, são exatamente aqueles que delas menos necessitam.

De fato, quanto maior o poder aquisitivo de determinada pessoa menos dependerá ela do Poder Público para a manutenção de sua saúde e de seus familiares, para a educação de seus filhos, para a defesa de sua propriedade, etc. Todavia, é essa pessoa, com reduzidas relações diretas de necessidade com o Estado-Administração, quem, pelo princípio da capacidade contributiva, deve contribuir mais para a Fazenda Pública.

Esse é o dilema que se coloca perante todos nós, quem necessita das ações estatais nāo tem como contribuir, enquanto quem tem como contribuir necessita muito pouco (ou não necessita) de intervenções estatais diretas (a não ser quanto à utilização da máquina estatal para evitar a revolta generalizada da massa excluída, que poderia pôr em risco seu estilo de vida)."

Além de muitos contribuintes não utilizarem grande parte dos serviços prestados pelo Estado, outra circunstância que mina o interesse em contribuir reside na complexidade do mundo atual e do papel desempenhado pelo Poder Público, de forma que no dia a dia de nossas vidas temos a falsa impressão de que não aproveitamos nada do Estado e da organização estatal e que, portanto, não devemos contribuir para sua manutenção. Esse ponto de vista foi ressaltado por Sven Steinmo, como se infere da passagem abaixo transcrita:

Em um influente artigo intitulado "Por que o Governo é tão Pequeno em uma Democracia" (1960), Anthony Downs apresentou o que acredito ser um dos dilemas centrais enfrentados em uma democracia moderna: Eleitores são muito desinformados, mas racionalmente egoístas. Primeiramente, tendo em vista que os benefícios são muitas vezes difusos, os cidadãos são incessíveis ou ignoram uma grande parte dos benefícios que eles recebem. Porque os tributos são diretos, os cidadãos estão penosamente conscientes dos custos do governo. Porque são racionais, eles se oporão a pagar por benefícios que não percebem. Considerando a complexidade do governo moderno e o escopo e alcance das atividades desempenhadas pelo mesmo, é difícil para os cidadãos avaliar com precisão os custos versus os benefícios: os cidadãos

11 Sobre esse tema ver: GUÉHENNO, Jean-Marie. O Futuro da Liberdade: A Democracia no Mundo Globalizado. Tradução Rejane Janowitzer. Rio de Janeiro: Bertrand Brasil, 2003, p. 51 e 52. 
sentem os custos do governo em forma de tributos diretos, enquanto benefícios como ar puro, boas estradas, mão-de-obra capacitada, defesa nacional e redução da pobreza são sentidos de forma muito menos precisa ou são pressupostos. ${ }^{12}$

Não é demais destacar que o trabalho de Steinmo teve por base a análise dos sistemas tributários da Suécia, dos Estados Unidos e da Inglaterra, países cuja realidade sócio-econômica é bem diferente da brasileira.

Todavia, se nem sempre se pode dizer que, no Brasil, viajamos por estradas bem conservadas, temos uma mão-de-obra capacitada fomentada pelo Estado, uma defesa competente da soberania nacional e conseguimos vislumbrar a redução da pobreza em nosso país, é verdade, por outro lado, que também aqui é possível verificar que nossa capacidade de identificar as atividades estatais em nosso proveito é pequena, sendo inverídico afirmar que o Poder Público nada faz em benefício daqueles que contribuem aos cofres públicos, mesmo que estes não sintam tais efeitos diretamente.

A despeito das considerações acima, cremos ser possível firmar, como segunda premissa deste estudo, a assertiva no sentido de que os contribuintes, por não perceberem os benefícios decorrentes do recolhimento dos tributos, tendem muitas vezes a deixar de recolhê-los.

\section{Delegação das atividades de arrecadação tributária aos contribuintes}

Em recente estudo publicado no Brasil, o Professor José Juan Ferreiro Lapatza fez importantes apontamentos sobre os sistemas de gestão tributária atualmente adotados pelos países europeus, separando o sistema anglo-saxão, baseado na autoliquidação dos deveres fiscais pelos próprios contribuintes, do sistema continental, fundamentado no exercício da liquidação tributária pela Administração Pública. ${ }^{13}$

Como menciona o próprio Professor Ferreiro Lapatza, os sistemas continentais têm sido influenciados pelo sistema anglo-saxão, de forma que há uma cada vez maior utilização da delegação ao contribuinte das atividades de liquidação fiscal em países como a França, a Itália e a Espanha. ${ }^{14}$

Em Portugal, essa mesma tendência foi apontada por José Luis Saldanha Sanches, ${ }^{15}$ deixando o mesmo registrado, logo na introdução de seu estudo sobre a

12 STEINMO, Sven. Taxation \& Democracy: Swedish, British and American Approaches to Financing the Modern State. New Haven: Yale University Press, 1993. p. 193.

13 LAPATZA, José Juan Ferreiro. Solución Convencional de Conflictos em el Âmbito Tributário: una Propuesta Concreta. In: TÔRRES, Heleno Taveira (Coord.). Direito Tributário Internacional Aplicado. São Paulo: Quartier Latin, 2004. p. 294.

14 Solución Convencional de Conflictos em el Âmbito Tributário: una Propuesta Concreta, 2004, p. 295-296.

15 SANCHES, José Luís Saldanha. A Quantificação da Obrigação Tributária: Deveres de Cooperação, Autoavaliação e Avaliação Administrativa. Lisboa: Lex, 2000. p. 75 e 76. 
quantificação das obrigações tributárias, "que o modo atual de execução das tarefas financeiras de obtenção de recursos pecuniários para o Estado tem como marca essencial uma redução do papel desempenhado pela Administração e o correspondente aumento da participação dos particulares nos procedimentos de aplicação da lei fiscal". 16

No Brasil, tal situação já era assinalada por Fábio Fanuchi na década de setenta, ${ }^{17}$ tendo sido objeto de análise pelo Professor Paulo de Barros Carvalho, que leciona:

Quando se fala em expedição de norma jurídica individual e concreta vem, desde logo, à nossa mente, o desempenho de um órgão da Administração ou Poder Judiciário. E, se passarmos apressadamente, sem refletir, essa idéia equivocada irá provocar um bloqueio, consolidando o preconceito de que $o$ administrado, na esfera de suas múltiplas possibilidades de participação social, reguladas pelo direito, esteja impedido de produzir certas normas individuais e concretas. Mas não é assim no direito brasileiro. Basta soabrirmos os textos do ordenamento positivo, no que concerne aos tributos, para verificarmos esta realidade empírica indiscutível: o subsistema prescritivo das regras tributárias prevê a aplicação por intermédio do Poder Público, em algumas hipóteses, e, em outras, outorga esse exercício ao sujeito passivo, de que se espera, também, o cumprimento da prestação pecuniária.

Diga-se de passagem, aliás, que tem havido um crescimento significativo na participação dos súditos do Estado, instados a praticar uma série de expedientes para a produção de normas individuais e concretas nesse campo. A transferência de atividades relativas à apuração do débito tributário para a esfera dos deveres instrumentais ou formais do sujeito passivo, mediante severo controle da entidade tributante, tornou-se uma viva realidade dos nossos dias. A maior parte dos tributos, hoje, assim no Brasil que em outros países que seguem o modelo continental europeu, estão cometidos ao sujeito passivo da obrigação tributária, cabendo-lhes estabelecer em fatos os eventos tributários, e relatar os dados componentes da relação jurídica. ${ }^{18}$

Assim, tendo em conta a proliferação, no Brasil, dos tributos sujeitos ao chamado "lançamento por homologação", as atividades de apuração e arrecadação tributária foram significativamente delegadas aos contribuintes, a quem cabe, na realidade, a

16 A Quantificação da Obrigação Tributária: Deveres de Cooperação, Autoavaliação e Avaliação Administrativa, 2000, p. 17.

17 FANUCCHI. Fábio. Curso de Direito Tributário Brasileiro. São Paulo: Resenha Tributária. 1971. v. I. p. 149.

18 CARVALHO, Paulo de Barros. Direito Tributário: Fundamentos Jurídicos da Incidência. São Paulo: Saraiva, 1998. p. 213. No mesmo sentido: COÊLHO, Sacha Calmon Navarro. Curso de Direito Tributário Brasileiro. 6. ed. Rio de Janeiro: Forense, 2001. p. 653; COSTA, Ramon Valdes. Estudios de Derecho Tributario Latinoamericano. Montevideo: AMF, 1982. p. 152; XAVIER, Alberto. Do Lançamento: Teoria Geral do Ato, do Procedimento e do Processo Tributário. 2. ed. Rio de Janeiro: Forense, 2002. p. 4 
realização das tarefas previstas no artigo 142 do Código Tributário Nacional como caracterizadoras do "lançamento tributário". 19

Diante dos comentários acima, é possível firmar a terceira premissa da presente exposição, segundo a qual no estágio atual da tributação, cabe aos contribuintes liquidar suas obrigações fiscais e recolher os tributos devidos, de acordo com sua autoliquidação, aos cofres públicos.

\section{A relevância assumida pelas atividades de fiscalização}

Partindo-se das premissas assentadas acima, no sentido de que:

(a) as receitas tributárias são um elemento indispensável para que o Estado possa dar cumprimento às suas atribuições; e de que

(b) em um sistema que depende de comportamentos não-provocados dos contribuintes, nem sempre estes estão dispostos a dirigir seu agir nesse sentido;

a fiscalização exercida pela Administração Pública, com a exigência do adimplemento dos deveres fiscais, a imposição das sanções cabíveis quando de seu inadimplemento e a utilização dos instrumentos estatais de coação sempre que necessário, é a última fronteira entre a eficácia das normas tributárias e o seu completo descrédito.

Nessa linha de idéias, é imprescindível que tal atividade de fiscalização seja desempenhada tendo como finalidade um só objetivo: a verificação da compatibilidade dos comportamentos dos contribuintes com os mandamentos legais, em estrita observância ao princípio da legalidade. Com isso, estariam resguardadas as necessidades fiscais do Estado (rectius, da coletividade), bem como a liberdade fundamental dos contribuintes de não serem submetidos ao recolhimento de qualquer tributo que não tenha fundamento no ordenamento jurídico tributário. Infelizmente, nada poderia estar mais divorciado da realidade fática.

Em primeiro lugar, dada a complexidade das normas fiscais, não raro surgem divergências entre a interpretação de determinada regra pelo sujeito passivo e a interpretação do mesmo dispositivo pela Fazenda, as quais geram cobranças consideradas indevidas pelo contribuinte.

Sobre a questão da proliferação das normas fiscais são pertinentes as palavras do Professor Victor Uckmar:

A urgência no legislar vai em detrimento da técnica e portanto da claridade. As dúvidas na interpretação ocasionam notáveis prejuízos, tanto para a administração como para os contribuintes, comportando, ademais, para os

19 Sobre o tema, ver o nosso Controle Administrativo do Lançamento Tributário: O Processo Administrativo Fiscal, 2004, p. 215-228. 
empresários, custos ainda não constituídos pela arrecadação, com grave prejuízo no plano da competência, especialmente internacional.

Frente a contrastantes interpretações de uma norma, quando o contribuinte escolha a mais favorável a si mesmo, assumirá a carga do risco de uma eventual verificação e o respectivo encurralamento constitui para a empresa um custo. E é por isso que é muito apreciado o instituto do ruling, que se deve regular com normas que assegurem objetividade e tempestividade: tal instituto, quando funciona, é de grande estímulo para ativar investimentos estrangeiros, como se sucedeu na Holanda. ${ }^{20}$

Nota-se, portanto, que um primeiro ponto de atenção relacionado à fiscalização tributária consiste nas cotidianas divergências interpretativas entre a Fazenda Pública e os sujeitos passivos, as quais fazem com que estes se encontrem em situação de potencial autuação a cada vez que aplicam as normas fiscais.

Ademais, conseqüência dos poderes atribuídos às autoridades fazendárias para fiscalização quanto ao cumprimento, por parte dos contribuintes, de seus deveres fiscais, foi o aumento das cobranças tributárias indevidas por parte daquelas, as quais são muitas vezes utilizadas como instrumento para exigência de pagamentos ilícitos por parte da fiscalização.

Assim. não raro os contribuintes vêem-se submetidos à lavratura de autos de infração em descompasso com as previsões da legislação tributária, os quais funcionam como instrumentos para a cobrança de vantagens indevidas por parte da fiscalização.

Assim, é possível firmar a última premissa deste estudo, no sentido de que no cenário em que atualmente se desenvolvem as atividades de arrecadação tributária, há várias situações em que podem surgir verdadeiros conflitos interpretativos entre a Fazenda e os sujeitos passivos, sendo certo, por outro lado, que a fiscalização tributária tem à sua disposição mecanismos para agir sobre os particulares, criando-lhes limitações e cobrando-lhes o recolhimento dos tributos mesmo na ausência de norma jurídica que preveja a incidência fiscal.

\section{Análise das premissas firmadas}

Considerando as seguintes premissas:

a) os tributos são a principal fonte de custeio das atividades estatais em um Estado Social;

20 UCKMAR, Victor. El Sistema Tributario: Las Instituciones, las Administraciones, los Contribuyentes. In: MELLO, Celso Antônio Bandeira de (Org.). Direito Tributário. São Paulo: Malheiros, 1997. p. 107. Sobre esta questão ver também: LAPATZA, José Juan Ferreiro. Poder Tributario y Tutela Judicial Efectiva. In: MELlO, Celso Antônio Bandeira de (Org.). Direito Tributário. São Paulo: Malheiros, 1997. p. 102. 
b) há uma propensão dos contribuintes a inadimplirem seus deveres jurídicos tributários;

c) via de regra, cabe aos sujeitos passivos de deveres fiscais apurar e recolher os tributos que lhes são cabíveis;

d) a fim de assegurar o cumprimento dos deveres fiscais por parte dos contribuintes, atribui-se às autoridades administrativas grandes atribuições relacionadas à físcalização dos comportamentos destes:

é possível concluir que o Sistema Tributário pátrio é marcado por controvérsias entre a fiscalização e os contribuintes, as quais resultam, no mais das vezes, de divergências dos mesmos quanto à correta interpretação dos fatos ou do direito aplicáveis a determinado caso concreto, ou de cobranças manifestamente indevidas formuladas pela Fiscalização com propósitos ilícitos.

Nesse cenário, é indiscutível a importância do processo administrativo fiscal, enquanto instrumento de controle da legalidade dos atos administrativos tributários, como se passa a examinar.

\section{A importância do processo administrativo fiscal}

Considerando que, em razão das peculiaridades do Sistema Tributário pátrio, os contribuintes estão sujeitos a constantes fiscalizações e cobranças por parte das autoridades fazendárias, formalizadas através da edição de atos administrativos, é imprescindível que o ordenamento coloque à sua disposição instrumentos para que se assegure que tal atividade desempenhada pela fiscalização irá se manter dentro dos marcos da legalidade. Essa é a razão existencial do processo administrativo fiscal.

É de se assinalar, desde já, que no âmbito do processo administrativo não há lide a ser solucionada, como pretende parte da doutrina. De fato, o processo administrativo fiscal corresponde a uma revisão da legalidade do ato tributário pela própria Administração Pública, de forma que somente haverá que se falar na instauração de lide entre Fazenda e sujeito passivo se, ao final do processo, manifestar-se aquela pela legalidade da cobrança. ${ }^{21}$

Nada obstante, o fato de não haver. quando da instauração do processo administrativo fiscal, lide a ser solucionada, em nada diminui a sua importância, tendo o mesmo as seguintes funções:

a) Legitimação da atividade estatal a partir da participação do sujeito passivo do dever tributário na formação do entendimento final da Fazenda Pública sobre a legalidade da cobrança formulada. ${ }^{22}$

b) Garantia dos direitos dos sujeitos passivos, assegurando-se-lhes a possi-

21 Sobre o tema ver o nosso Controle Administrativo do Lançamento Tributário: O Processo Administrativo Fiscal, 2004, p. 116-118.

22 Cf. Controle Administrativo do Lançamento Tributário: O Processo Administrativo Fiscal, 2004, p. $13-18$. 
bilidade de questionar a legalidade de cada ato administrativo de exigência fiscal que lhe seja encaminhado. ${ }^{23}$

c) Controle da Administração Fazendária, abrindo-se ao sujeito passivo a possibilidade de argüir e utilizar de todos os meios lícitos para demonstrar a ilegalidade do ato administrativo de cobrança. ${ }^{24}$

d) Melhor aplicação das regras tributárias, já que a participação do sujeito passivo possibilita a prática de um ato administrativo fiscal que melhor represente os fatos como efetivamente ocorridos, com uma mais correta aplicação das normas fiscais. ${ }^{25}$

Nessa linha de entendimentos, percebe-se que o processo administrativo fiscal é de extrema relevância para o bom funcionamento do Sistema Tributário, sendo um instrumento democrático de legitimação, garantia, controle e revisão dos atos administrativos tributários.

Em um Sistema Tributário como o brasileiro, o qual é marcado pelo conflito entre os contribuintes e a Fazenda Pública, a existência de um processo administrativo fiscal que cumpra sua função institucional previne o surgimento de litígios, evitando que muitas discussões sejam apresentadas ao Poder Judiciário.

Ademais de todo o exposto, considerando que os textos legais muitas vezes dão margem à extração de normas jurídicas distintas, o processo administrativo é também o campo onde Fazenda e contribuinte discutem dialeticamente a fim de determinar a norma aplicável a determinado caso concreto.

Dessa forma, é indispensável a valorização do processo administrativo fiscal, a qual passa (a) pela garantia da independência técnica do órgão responsável pela revisão dos atos administrativos tributários, que garante que suas decisões serão pautadas apenas pela realização da legalidade fiscal; e (b) pelo cumprimento. pela Administração Fazendária, das decisões proferidas no processo, repudiando-se, assim, o seu questionamento pelo próprio Fisco. seja internamente, por via do recurso hierárquico, seja externamente, perante o Poder Judiciário.

Diante do cenário acima apresentado, é imprescindível que os operadores do Direito Tributário se apercebam da grande relevância do processo administrativo fiscal, lutando pela sua evolução em direção à existência de órgãos julgadores capacitados tecnicamente, cujas decisões devem ser lastreadas por fundamentos jurídicos e não políticos.

Apenas quando tivermos instrumentos adequados de controle dos atos administrativos fiscais teremos alcançado um Sistema Tributário que protege os contribuintes contra cobranças indevidas, sendo que não parece razoável que a responsabilidade por tal controle seja entregue apenas ao Poder Judiciário, havendo grande papel a ser desempenhado pela Administração Pública nesse particular.

23 Cf. Controle Administrativo do Lançamento Tributário: O Processo Administrativo Fiscal, 2004 , p. $18-20$.

24 Cf. Controle Administrativo do Lançamento Tributário: O Processo Administrativo Fiscal, 2004. p. $20-22$.

25 Cf. Controle Administrativo do Lançamento Tributário: O Processo Administrativo Fiscal, 2004, p. 22. 